\title{
O verbo lúdico de João Claudio Arendt: entrevista
}

\section{Vitor $\mathrm{Cei}^{1}$}

\section{Resumo}

João Claudio Arendt tem se destacado no cenário da literatura contemporânea do Rio Grande do Sul. A presente entrevista foi feita em maio de 2016, como atividade da disciplina "Literatura em devir", então ministrada pelo professor Vitor Cei no curso de Letras-Português da Universidade Federal de Rondônia. O trabalho contou com o apoio das discentes Cleiza Teixeira da Silva Souza, Michele Batista Lemes, Nilian Pereira Guimarães e Sara Pereira dos Santos. Em outubro de 2017 foi acrescentada a última pergunta, contemplando o projeto de extensão "Notícia da atual literatura brasileira: entrevistas", que é um esforço no sentido de mapear a literatura brasileira do início do século XXI a partir da perspectiva dos próprios escritores. Arendt discorre sobre seu processo de escrita criativa, avalia a recepção de sua obra e reflete tanto sobre aspectos relativos à literatura brasileira quanto sobre o quadro político e cultural dos últimos anos e as respostas éticas por ele demandadas.

Palavras-chave: João Claudio Arendt; poesia; literatura brasileira contemporânea

${ }^{1}$ Doutor em Estudos Literários (UFMG). Professor da Universidade Federal de Rondônia. Líder do grupo de pesquisa Ética, Estética e Filosofia da Literatura. 


\section{Abstract}

João Claudio Arendt has stood out in the contemporary literature scene from Rio Grande do Sul. This interview was made in May 2016, as an activity of the course "Literature in Devir", at that time taught by Professor Vitor Cei. The work was supported by Cleiza Teixeira da Silva Souza, Michele Batista Lemes, Nilian Pereira Guimarães and Sara Pereira dos Santos, language and literature students from the Federal University of Rondônia. In October 2017 the last question was added, to attend the extension project "News from Current Brazilian Literature: Interviews", which consists of a mapping of Brazilian Literature of the beginning of the 21st century from the perspective of the writers themselves. The poet gives her account on her own creative writing process, assesses the reception of her work, and reflects upon aspects pertaining to Brazilian literature as well as upon the political and cultural framework of the latest years and the ethical response demanded by them.

Keywords: João Claudio Arendt; poetry; contemporary Brazilian literature

\section{Apresentação}

João Claudio Arendt nasceu em 1970, em Cunha Porã (SC), e cresceu no interior de Carazinho (RS), tendo recebido educação bilíngue Português-Hunsrückisch, variedade dialetal do alemão mais falada no Brasil, principalmente nos estados de Santa Catarina e Rio Grande do Sul. Aos 15 anos de idade foi estudar em internato protestante em Ivoti (RS), onde aprendeu o alemão padrão. Depois de viver em São Leopoldo (RS) e Bento Gonçalves (RS), em 2007 estabeleceu residência em Caxias do Sul(RS).

Em sua trajetória acadêmica, Arendt fez Estágio Pós-doutoral no Instituto de Estudos Latino-Americanos da Universidade Livre de Berlim (2011), doutorado em Lingüística e Letras (Teoria Literária) pela Pontifícia Universidade Católica do Rio Grande do Sul(2000), mestrado emHistória 
pela Universidade do Vale do Rio dos Sinos (1996) e licenciatura Plena em Letras Português/Alemão pela Universidade do Vale do Rio dos Sinos (1993). Atualmente atua nos Programas de Mestrado em Letras e Cultura da Universidade de Caxias do Sul e de Doutorado em Letras - Associação Ampla UCS/Uniritter. Também é diretor da Revista Eletrônica Antares (Letras e Humanidades). Desenvolve pesquisas sobre literatura brasileira e sul-riograndense, com foco em imaginário social, identidade regional, regionalidade, leitura e recepção.

Poeta premiado, Arendt estreou em livro em 2004, com Histórias de um Bruxo Velho: ensaios sobre Simões Lopes Neto, publicado pelaEDUCS. Dois anos depois, em conjunto com os poetas Clóvis Da Rolt, Douglas Ceccagno e Marli Tasca Marangoni, Arendt publicou Calendário-Antologia poética do Grupo Neblina, volume coletivo contendo os poemas dos quatro integrantes do grupo. Em 2008, o livro Plural da Ausência foipremiado no $42^{\circ}$ Concurso Anual Literário de Caxias do Sul (RS), sendo publicado em 2009 como selo daBiblioteca Pública MunicipalDr.Demétrio Niederauer. Em 2013 lançou o livro bilíngue Quadros Berlinenses: poesia/Berliner Bilder: Gedichte, com tradução/recriação para o alemão de Sarita Brandt.

João Claudio Arendt insere-se no seleto grupo dos poetas brasileiros do século XXI que apresentam apuro da linguagem e assinatura forte. Ao escrever e publicar seus versos, dentre os quais encontramos haicais, dísticos, tercetos e poemas sem metro e sem rimas, o escritor elabora a vivência (Erlebnis) e a experiência (Erfahrung) de seu percurso por locais de memória, seja o varal de roupas no quintal de uma casa ou o campo de concentração nazista Sachsenhausen. Assim, na medida em que aborda individualidades, sua escrita reelabora as marcas de contextos sociais que dizem respeito à história de uma coletividade.

Como todo autor de haicais, Arendt também observa atentamente as lições da natureza - das estações do ano aos vôos dos pássaros, passando pelas flores e pelo orvalho. Dentre as inúmeras formas de contemplar e aprender com a natureza, se destaca o uso poético de elementos das 
estações do ano (especialmente do outono). Por vezes, podemos perceber a natureza como lugar de projeção de conteúdos sentimentais, como em "Fim do outono", de Quadros Berlinenses: "Perdidas as últimas folhas, / não nos resta outra coisa/ senão esperar" (ARENDT, 2013).

$\mathrm{Na}$ entrevista a seguir, Arendt reflete a respeito de matizes de seu processo de composição literária e da recepção de sua obra, comenta sobre o cenário da poesia brasileira contemporânea e compartilha com o leitor reflexões tanto a respeito do quadro político e cultural dos últimos anos, quanto sobre as respostas éticas por ele demandadas. Confira a entrevista e aprecie os poemas do livro Quero e outros poemas (inédito) selecionados para esta edição da Revista Leitura.

\section{Cada escritor possui um modus operandi, por assim dizer...} Fale um pouco sobre o seu processo criativo. Houve um momento inaugural ou o caminho se fez gradualmente? Em que momento da vida você se percebeu um escritor?

Posso afirmar que o meu processo criativo é contínuo, ininterrupto. Mas isso não significa que eu escreva o tempo todo... Explico: a leitura, o olhar atento ao entorno, a contemplação e até uma certa alternância de humor fazem parte do processo criativo como um todo. $\mathrm{O}$ ato de criação, para mim, não é apenas aquele reservado a registrar algo no papel ou na tela do computador, pois sentir, ver e pensar já são atitudes de criação.

Não digo que houve um momento único que possa ser considerado inaugural para minha escrita. Acho que tive uma iniciação gradual, desde a infância, na convivência com livros, que sempre despertaram a minha curiosidade, e com as muitas histórias contadas no ambiente familiar. Tive uma infância pobre no campo, mas nunca faltou o alimento intelectual. Os meus pais possuíam alguns livros, eram leitores e sempre incentivavam o estudo. E há outro aspecto muito interessante nesse contexto familiar, que 
são os jogos delinguagem: a famíliainteira sempre foidadaaostrocadilhos, às ironias, às ambiguidades, aos trava-línguas, ao verbo lúdico em suma. E eu acho que foi dessa forma que desenvolvi a intimidade com a linguagem. Mas só me percebi como escritor no momento em que entendi que, com a linguagem, eu poderia criar tanto os meus abismos, quanto as minhas pontes para andar sobre eles.

\section{Você se inspira em algum cânone da literatura brasileira?}

Eu tenho meus amores na literatura brasileira, especialmente na poesia. Gosto muito de alguns românticos e simbolistas. Mas é entre os modernistas que estão os meus eleitos: Manuel Bandeira, Cecília Meireles, Carlos Drummond de Andrade e Ferreira Gullar, por exemplo. Dos alemães, gosto muito do Rainer Maria Rilke. E de Portugal, fico com Fernando Pessoa.

\section{Você está escrevendo algum livro no momento ou continua a escrever poesia com frequência?}

Na verdade, eu não tenho em mente “escrever livros". Eu escrevo poemas que podem ser reunidos em forma de livro, a partir de uma seleção posterior. Geralmente, redijo aquilo que rumino mentalmente e sinto durante alguns dias... Tenho material para dois ou três livros, inclusive de poesia infantil.

\section{O que você acha dos escritores brasileiros contemporâneos? Ou, afastando a pergunta de nomes específicos, para pensar a poesia brasileira atual como um todo: $O$ que você vê?}

É difícil responder a essa pergunta... Mas eu vejo muita ansiedade por parte dos escritores para publicarem suas produções. Não consigo imaginar que alguém tenha "conteúdo" para escrever e publicar dois ou três livros por ano - livros 
que sejam realmente bons. Claro que há a produção por encomenda, os surtos criativos, os projetos coletivos. Mas eu acredito no "tempo de gaveta", na avaliação por pares, na discussão dos textos etc. Poucos são os escritores que viveram de direitos autorais e conseguiram produzir obras que resistiram ao "tempo de prateleira".

\section{Como você vê a recepção de sua obra? As suas poesias são voltadas para qual público?}

Minha recepção é bastante regional e eu não esperava nada diferente, tendo em vista a abrangência das editoras. Também não invisto muito numa carreira literária, não fico bajulando leitores ou editores. E a carreira acadêmica, o ganha-pão,temmetomado grandepartedasenergias, com aulas, coordenação, orientações, publicações etc... O livro Quadros berlinenses tem uma boa recepção por causa do formato bilíngue e já foi mencionado por críticos na Alemanha. O Plural da ausência teve resenha e artigo em periódicos acadêmicos no Brasil, e foi leitura obrigatória para o vestibular da Universidade de Caxias do Sul em 2013. Não fazer uma carreira literária meteórica como certas figuras que conheço e ter uma recepção regional não me incomoda. Muito pelo contrário.

\section{Quais os principais desafios para a edição de novos escritores no Brasil de hoje?}

Acho que o desafio está em fazer boa literatura. O papel aceita tudo, e editora qualquer um pode contratar.

\section{Você considera importante que o professor de Literatura também seja escritor?}

Não vejo relação de dependência entre as duas coisas. Conheço ótimos professores de literatura que nunca redigiram um verso sequer e 
se satisfazem com a interlocução dos alunos ou de outros leitores. Um médico não precisa sofrer da mesma doença dos seus pacientes, para ser um bom médico... Um professor de literatura deve gostar, basicamente, de três coisas: literatura, alunos e ensino.

8. Você percebe de imediato aqueles alunos que têm talento para escrever, ou seja, que já são escritores e prescindem da academia?

Ninguém deveria prescindir de formação acadêmica, nem mesmo o pedreiro. O meio acadêmico é hoje o melhor espaço de formação intelectual e pode ser também o espaço ideal para a formação do escritor. A universidade possibilita aprofundar conhecimentose dáacesso aumtipo de (con)vivência que não existe fora dela. Os alunos, mesmo os talentosos para a escrita, quase sempre são imaturos e precisam de lapidação.

\section{Em seus livros Pluralda Ausência e Quadros Berlinenses podemos} ler muitos haicais. Por que a preferência por essa forma poética?

Em Quadros berlinenses, predominam os haicais. Mas, em Plural da ausência, há apenas alguns. Do ponto de vista formal, eu gosto de ler e escrever poemas curtos, como o haicai ou o dístico, o terceto e a quadra, em razão do trabalho de síntese que eles requerem. O haicai sempre busca expressar uma relação com a natureza, as estações do ano, as fases da vida, a transitoriedade etc., e como eu sou muito bucólico, contemplativo e imagético, 'o haicai / bem como luva / me cai...'

10. Como foi a experiência de escrever Quadros Berlinenses, livro bilíngue, em coautoria com a tradutora Sarita Brandt? Qual foi o modus operandi da tradução da língua portuguesa para a alemã?

Na verdade, eu escrevi os poemas durante o outono, entre setembro e dezembro de 2011, em Berlim. Mas foi em janeiro de 2012 que eu e a 
Sarita Brandt nos reunimos para acertar e discutir a versão dos poemas para o alemão. Todavia, ela acabou assumindo mais do que a tarefa, às vezes, mecânica da tradução, porque muitos poemas precisavam ser afinados com a cultura alemã. Quem trabalha com tradução de poesia sabe do que estou falando. Tanto é, que a tradução levou quase doze meses, entremeada que foi de conversas por Skype e tentativas fracassadas de chegar a versões satisfatórias. Em suma, o que inicialmente deveria ser tradução transformou-se em autoria.

\section{Atualmente, no Brasil e no exterior, vivemos a ascensão de uma} onda reacionária que traz em si matizes racistas, fascistas, misóginos e homofóbicos. Gostaríamos que você nos ajudasse a compreender: onde estava guardada tanta monstruosidade? Houve um ponto ou marco crucial para a detonação de uma circunstância como esta que vivemos hoje? O que você imagina ou espera como desfecho do atual estágio da humanidade?

Essas questões são difíceis de responder em poucas linhas. Mas, como professor, eu diria, de modo bem sintético, que vacilamos ao não darmosadevidaatenção ao papel da linguagemnaeducação infantil, básica e superior. Nós nos constituímos cidadãos à medida que a linguagem nos insere e nos situa na sociedade, na cultura e na história. E é com a linguagem que também atuamos sobre elas.

Como pesquisador, eu diria que a História écíclica. Basta olharmos para trás, que veremos, logo ali, as coisas acontecendo como já haviam acontecido antes. Cada geração traz consigo valores que deram sentido à geração anterior, e eles são acionados como forma de defesa em momentos de crise. Não existe ruptura total, nem pode haver, porque isso significaria o aniquilamento de uma geração. A geração que hoje defende o regime militar, que manda fechar exposições de arte e que não aceita a diferença é a que nasceu durante o regime militar, e que agora se encontra no auge 
da sua atuação política, econômica e social. E ela não foi perseguida, torturada e censurada como a geração que a antecedeu...

Como poeta, eu obviamente poderia dizer que nos falta literatura. Mas não é isso. O escritor e a literatura não estão a serviço da sociedade, e sim da linguagem, a qual, como eu disse anteriormente, nos insere e nos situa na sociedade, na cultura e na história. A literatura - ou a arte em geral - não transforma pessoas más em seres bons, demônios em anjos, e assim por diante. Conheço gente que escreve ou dá aula de literatura agindo de forma intolerante e mesquinha ao defender valores que julga ideais para o mundo que sonha construir (para si, obviamente!).

Se haverá desfecho para o que estamos vivendo agora? Eu diria que isso não é o começo, mas sim o fechamento de um ciclo. Como disse Ferreira Gullar, "Caminhos não há, mas os pés na grama os inventarão".

\section{Referências}

ARENDT,João Claudio. Quadros Berlinenses: poesia; Berliner Bilder: Gedichte. Trad. Sarita Brandt. Caxias do Sul: Editora Maneco, 2013.

.Plural da ausência. 1. ed. Caxias do Sul: Biblioteca Pública Municipal Dr. Demétrio Niederauer, 2009.

. Histórias de um Bruxo Velho: ensaios sobre Simões Lopes Neto. 1. ed. Caxias do Sul: EDUCS, 2004.

DA ROLT, Clóvis; CECCAGNO, Douglas; ARENDT, João Claudio; TASCA, Marli. Calendário - Antologia Poética do Grupo Neblina. Bento Gonçalves: Edição dos autores, 2006. 


\section{Anexo: Poemas inéditos de João Claudio Arendt}

\section{Outono I}

De onde vêm,

folhas ao vento?

Para onde vão?

\section{No varal}

A roupa à espera da chuva

ou do vento que a carregue

\section{Incerteza}

Não há sol

não há lua

nem voo de pássaro

que se iguale a nós

Chegaremos vivos

à próximaestação? 
Consumirás tua beleza entre o inútil trabalho e os sermões da igreja

Cuidarás do teu filho como de um espelho, onde ocultas emvão as tuas rugas de tristeza

E à noite, na alcova, acolherás no ventre, como na terra a cova, da espécie humana a daninha semente 


\section{Repousa o bife sobre a mesa}

Pulsa-lhe ainda

a vitalidade do boi subjugando o campo?

Porque o sumo - ainda sangue -

fabrica vasos

na carnadura estéril da porcelana

Na urgência por talheres

submete-se o bife

ao repasto das moscas 
Quando se extinguir

a água dos varais

e os frutos nos galhos

perderem o equilíbrio

Quando tudo em mim for debilidade e velhice

e a sombra unificar todos os matizes

- ungirei meucorpo

com algas e espuma

e alimentarei as ondas

que desafiam recifes 
Bem-aventurada a treva

onde germinam degredos

Bem-aventurada a dor

que se colhe como fruto

Bem-aventurada a fome

pelo pão que não se parte

Bem-aventurada a guerra

com sua ascese de sangue

Bem-aventurada a jura

do que nunca se cumprirá 
Quero a santidade das putas

e a safadeza das castas

Quero as uniões dissolutas

e as relações nefastas

Quero a luxúria,

a lascívia e as paixões devassas

Quero a mãe, quero a filha

e o ódio das madrastas 